desert animals, but is not related to the animal's contacts with other animals.

Value in colour in the biological environment implies that the animal seeing it has colour vision. As Dr. Pumphrey showed, only some arthropods and some vertebrates have been shown experimentally to have this faculty. Perhaps some cephalopods should be added, on the evidence of their natural behaviour and not on experimental results. Such evidence may be as conclusive as the experimental.

Wherever colour is of value in the interactions of animals, except in the rare cases where the stimulus is a simple flash of colour, pattern appreciation as well as colour perception is necessary in the observing animal. It is therefore not surprising that a colour sense and an image-forming $\theta y \Theta$ are associated in animals, for pattern appreciation is the characteristic of image-forming eyes.

In recognition of an animal by another, two distinct components of the process of recognition must be distinguished. First, the animal must be recognized as a discrete object on its background. This is prevented by the various forms of camouflage. Secondly, the animal must be recognized as of a particular kind-for example, of a kind suitable as food. To understand how the second can be prevented by adaptation in colour and pattern, we need to know how animals recognize the kinds of objects.

In much of their behaviour, animals, even such complex animals as birds and insects, recognize the kinds of objects not by an aggregate of many characters, as we do, but by one, or at most a few, 'valent' characters, such as the smell, shape, colour, pattern or type of movement. Not all animal behaviour is of this simple type; but so far as it is a resemblance that includes the valent characters will be effective, although in other characters there is no resemblance. But if an animal is exposed to predators of many species, a detailed and complicated resemblance may be built up by combining the different valent characters required by the various species. We can thus see how the astonishingly accurate resemblances we find in Nature may have originated from very partial resemblances which, in spite of their incompleteness, would still have had some value.

G. S. CARTER

\section{PHYSIOLOGY OF LACTATION}

A T a joint meeting of Sections M (Agriculture) and I (Physiology) of the British Association, held at Brighton on September 14, recent research on the physiology of lactation was discussed. Prof. $H$. Hartridge, president of Section I, was in the chair. The discussion was introduced by Prof. H. D. Kay (National Institute for Research in Dairying, Shinfield) who said that in view of the importance of lactation both from the human and from the industrial points of view, it is remarkable that the physiology of the mammary gland had, until recent years, received so little attention. During the past dozen years, however, knowledge has advanced substantially as regards the endocrine control of mammary development and of milk secretion, including the artificial induction of lactation in the virgin or barren animal, the hormonal inhibition of lactation, the cytology of the gland in relation to function and the 'let-down' of milk as a conditioned neuro-hormonal reflex. The biochemistry of milk secretion, including both glandular metabolism and the factors affecting milk composition, have also undergone active study. Advances in knowledge of the neuro-hormonal mechanisms by which the mammary gland is controlled are already beginning to influence both milking technique and also clinical methods of dealing with problems of human lactation.

There is a very rapid blood-flow through the actively secreting gland, and a large consumption of oxygen. The respiratory quotient of the secreting tissue is, in the intact animal, well above unity, and in surviving slices of tissue suspended in a nutrient solution, figures as high as $1 \cdot 5-1 \cdot 6$ have been obtained by $\mathrm{T}$. $\mathbf{H}$. French, suggesting fat formation from carbohydrate. A major difficulty in recent biochemical studies in the intact animal is the uncertainty of the extent of error due to lymph drainage, and all findings depending on arterio-venous changes must be interpreted very cautiously.

The practical significance was pointed out of the recent work of Dodd and Foot at Shinfield, who have found that more than 50 per cent of the fat originally present in the secreted milk in the bovine udder is not removed during the ordinary process of milking. Very recent findings which indicated that milk composition might be influenced by naturally occurring cestrogens present in young grass and clover were also described. The relationship between the texture of the teat and liability to udder infection, established in the last few months by J. I. Taylor at Compton, was mentioned as a new factor that seems of importance in buying or breeding a cow.

Mr. K. C. Richardson (University College, London) described with the aid of slides some of the results of his recent studies of the cytology of the mammary gland in relation to function. The milk-secreting alveoli are not usually spherical, but are rather elongated structures, the secreting cells of which show great changes in shape and size at different stages in the secretory cycle. The synthesized milk constituents pass from these cells into the alveolar lumen by recurrent rupture of the cell membrane. Whether or not there are nerve fibres ending in the secretory tissue is as yet unsettled, the available histological technique being insufficiently specific. $\mathrm{He}$ discussed the possible mechanism of 'let-down'. There is no doubt that during 'let-down' active pressure is brought to bear on the milk which has been secreted into the alveoli. Smooth muscle, though present in the mammary gland, is neither in the right places nor in sufficient quantity to make any serious contribution to the 'let-down' phenomenon. There are no sphincters on the ducts emerging from the lobules. However, as a result of a recent advance in histological technique, clear evidence has been obtained of the abundant presence in the gland of myo-epithelial cells, the large nuclei of which are usually to be found between the alveolar secreting cells and the basement membrane, and the processes of which can be shown to extend over the outer surface of each alveolus. Convincing histological evidence was brought forward by $\mathbf{M r}$. Richardson that these cells can and do contract at 'let-down'; the basket structure, tightly embracing the distended alveolus before 'let-down', does not become flaccid when the milk has been forced out and the alveolus diminished in size, but remains taut.

Dr. S. J. Folley (National Institute for Research in D.xirying, Shinfield) briefly mentioned three stages 
in the history of research on the control of the mammary gland In the earliest stage, the control appeared to be mainly of neural origin; but the establisl ment of the fact that mammary tissue could actively secrete when removed from any nerve connexion with the rest of the body, together with experiments showing the great importance of hormonal influences on the gland, led for a time to mammary physiology becoming almost a branch of endocrinology. The more balanced, modern view that neural and hormonal influences must be considered together in obtaining a satisfactory picture of the growth and function of this gland is now supported by increasing evidence. Thus the sucking stimulus apparently causes reflex secretion of prolactin by the anterior pituitary, by a pathway not yet understood, and is of importance not only in initiating milk secretion but also in maintaining it and in indirectly preserving the structural integrity of the milk-producing tissue.

The milk already secreted by the gland is, before suckling or cowshed milking, present in two portions. One can be obtained from the gland cisterns in the cow by careful cannulation (avoiding nervous stimulation); the other portion of the milk is more tenaciously held in the smaller ducts and capillaries and has to be forced out by an active (but involuntary) process. This latter process, 'let-down', though activated by a posterior-pituitary hormone, is in the intact animal a nervous reflex that can become conditioned, and is easily inhibited, both in the bovine and in the human. In the denervated udder, or in the isolated, perfused gland, 'let-down' can, however, be readily brought about by the introduction of oxytocin into the circulating blood. There is no evidence for the 'erection' of udder tissue by engorgement with blood; the true nature of the contractile tissue in the gland, hitherto uncertain, has now been established for the first time by the experiments just deseribed by Mr. Richardson.

Dr. K. L. Blaxter (Hannah Dairy Research Institute, Ayr) described recent applications to dairy cattle of hormonal treatment for initiating or increasing milk secretion. Widespread treatment of thousands of normal animals presupposes a large supply of endocrine preparations, and for this reason synthetic sources of hormones are of the greatest potential use; synthetic œstrogens and iodinated proteins containing thyroxine can now be made on a large scale.

Lactation in barren cows and virgin heifers can be induced in a large proportion of such animals, though not, apparently, in all, by administration of synthetic œstrogens of the stilbœstrol type. There is great individual variability in the quantitative response to such treatment, for reasons that are not yet clear. Another practical handicap is that the treated animals are 'on heat' during the whole period during which the ostrogen is being administered; this leads, if the treated animals are allowed to run with other cows, to coital mimicry and the serious risk of pelvic fracture, since the ostrogen causes relaxation of the pelvic ligaments.

The feeding of iodinated proteins to lactating cows induces an increase in milk production, the magnitude of which depends on the dose given to the cows. A reasonable practical increase, say, of 20-25 per cent, can readily be obtained. Experiments were described showing the effect of such treatment on both milkyield and composition and on the condition and behaviour of the animals. The milk obtained after feeding iodinated protein shows no thyroxine-like effect when taken in quite large quantities by human consumers, though its iodine content is increased. From the economic point of view, the value of the extra milk produced is considerably greater than the cost of the iodinated protein plus the extra feeding stuffs required. The margin of safety between an optimal dose and one which causes breakdown in the cow is not sufficiently large to allow the material to be used by other than competent farm staff. So far, in experiments lasting several months during which carefully controlled quantities were fed, there were no bad effects on the cow's health either at the time or in the next lactation; but until long-range experiments, now in progress, are completed, iodinated protein feeding cannot be regarded as a practical method for increasing the nation's milk supply.

Dr. Gaines (Glasgow) showed, by lantern and microscope, recent results of histological examination of human nipples. There are very abundant nerve endings in the nipple, many of them associated with smooth muscle cells, and associated with the erection that takes place after stimulus. The sucking stimulus of the infant is remarkable-the suction on the nipple could be as great as 100 or even $200 \mathrm{~mm}$. of mercury. So far, though their presence had formerly been assumed in the nipple, no Meissner corpuseles had been found.

A discussion followed the papers referred to above.

\section{PRIMITIVE TECHNIQUES, AGRICULTURE AND ECONOMIC ORGANISATION}

DRIMITIVE techniques and their influence upon economic organisation was the subject of a discussion in Section $\mathbf{H}$ (Anthropology) of the British Association on September 10 at Brighton. Mr. R. U. Sayce, president of Section H, was in the chair.

The discussion was opened by Mr. Adrian Digby, who laid stress on the importance of the time factor. The study of society and the study of technology have, he said, been drifting apart under the influence of the functional school. The welter of elosely integrated, not to say tangled, data with which social anthropologists have to deal has led those with leanings towards sociology to jettison the study of material culture as of least value to their particular interests and to specialize in social structure as a way out of their difficulties. On the other hand, those interested in material eulture have paid more attention to the 'anatomy', as it were, than to the 'physiology' of their material. But there is a very close relation between social organisation and the manner in which people set about satisfying their needs in life.

There are, said Mr. Digby, six essential factors necessary to the daily life of any community : namely, (i) food, (ii) clothing, (iii) housing, (iv) fuel, (v) social integration for the distribution of the results of labour, and for security, and (vi) social integration for emotional and intellectual satisfaction. Under this latter head he included religion, marriage and relaxation. The relative importance of these six factors would vary according to circumstances, but the growth of any one in importance, or in time occupied, would be at the expense of some 